\title{
Developing Safety Cultures in Amtrak and WMATA
}

\author{
By Mark Buckley, Keith Marfione, and Hannah Putman
}

Amtrak and the Washington Metropolitan Area Transit Authority (WMATA) have made recent efforts to improve their organizational safety cultures. By transforming their values and behaviors, these transportation organizations sought to reduce employee and passenger accidents and injuries, as well as build more collaborative cultures. This paper illustrates case studies of Amtrak and WMATA and examines the strategies and promising practices that these organizations employed to improve their safety cultures.

\section{Introduction}

On June $22^{\text {nd }}, 2009$, as commuters traveled home from work, two Washington DC metro trains collided. Nine people died and dozens more were injured in an accident that the National Transportation Safety Board called inevitable (Scott Tyson 2010). While the immediate cause of the crash was malfunctioning equipment that failed to detect a train stopped on the tracks, the metro system's inadequate safety culture was the deeper underlying cause. This accident prompted the Washington Metropolitan Area Transit Authority's (WMATA) metro system to improve its safety culture at the same time that Amtrak, another rail system, was taking steps toward a similar initiative. This study explores the respective safety cultures at Amtrak and WMATA and the processes that each organization used to develop and implement these cultures.

Both Amtrak and WMATA are subject to public funding and oversight, and are responsible for the safe passage of thousands of people each day. Congress created Amtrak by passing the Railroad Passenger Service Act on October 30, 1979. Currently, Amtrak serves an average of 74,00o passengers each day in approximately 300 trains over more than 40 routes (Amtrak 2010). The railroad has roughly 20,000 employees and its fiscal year 2010 appropriation from the US Congress was $\$ 1.55$ billion. WMATA, which opened its first rail segment in 1976, provides rail, bus, and paratransit service to the Washington, DC metropolitan area. This study focuses on the safety of the Metrorail component of WMATA. WMATA receives funding through fares and advertising and subsidies from Maryland, Virginia, and DC, in addition to federal funding for specific purposes such as anti-terrorism efforts and safety improvements (Schultz 2011; Halsey 2011). Metrorail has an operating budget of $\$ 822$ million. As of December 2010, the average weekday ridership on the Metro system was 647,343 people (Office of Performance 2011). WMATA currently serves 86 stations along 106 miles of tracks with 1,118 rail cars in service.

\section{Background}

Organizational safety culture, a relatively new concept in modern society, first appeared formally in the International Nuclear Safety Group's 1986 report on the Chernobyl nuclear disaster in Ukraine. The report described safety culture as "that assembly of characteristics and attitudes in organizations and individuals which establishes that, as an overriding priority, nuclear plant safety issues receive the at- 
tention warranted by their significance" (International Nuclear Safety Group 1986). Research on safety culture has increased largely because of public outrage over major incidents like the 1986 Space Shuttle Challenger disaster and the 1989 Exxon Valdez oil spill. Experts have identified the lack of a strong safety culture as a major contributing factor in several recent large-scale catastrophic accidents, including the 2005 explosion at a BP oil refinery in Texas City, TX and the Washington DC Metrorail collision in 2009 (Department of Transportation 2010).

There is no universal definition of safety culture or set of characteristics that embodies safety culture in all organizations. Much of the discussion focuses on whether safety culture should concentrate on changing people's behavior or their attitudes and beliefs. The US Department of Transportation (DOT) has recently prioritized identifying vulnerabilities in safety culture throughout all of its agencies. As a part of these efforts, DOT has defined safety culture as the "shared values, actions, and norms that demonstrate a collective commitment to emphasize safety over competing goals and demands." DOT further concluded that safety culture exists within three organizational realms: psychological, how people feel; behavioral, what people do; and situational, what policies, procedures, and management systems the organization has in place (Department of Transportation 2010).

The National Transportation Safety Board (NTSB) describes an effective safety culture as having four successful and concurrent cultures. An organization must have an informed culture in which everyone understands the factors that affect safety, a reporting culture in which people feel encouraged to report safety concerns, a just culture in which people can report safety concerns without fear of blame, and a learning culture in which the organization can learn from safety information and implement necessary reforms (Sumwalt 2009).

\section{Research Questions}

The research team developed a set of questions to explore how each organization views the concept of safety culture. The overarching research question is: What are the promising practices and lessons learned from the development of safety cultures within Amtrak and WMATA?

To answer this central question, the research team devised specific research questions to determine the dynamics of the two organizations' distinct safety cultures. These research questions provided a foundation for interviews with various Amtrak and WMATA representatives. They are as follows: 1. How do Amtrak and WMATA define safety culture?

2. What prompted these organizations to develop their safety cultures?

3. What did each organization do to improve its safety culture?

4. What lessons did each organization learn during its safety culture transformation?

Table 1 presents the framework that the team used to explore research questions and conduct interviews. The interview questions the team developed served as a guide, not a script. As such, the interview questions represent the topics addressed during actual interviews.

\section{Scope and Methodology}

To explore the safety culture models of Amtrak and WMATA, the research team collected data in two ways. First, the team researched contemporary reports and official documents in three areas of inquiry at both Amtrak and WMATA: safety culture as a general concept, safety practices, and results. Next, the team conducted nine interviews: three with WMATA staff (including the chief safety officer), three with Amtrak staff (including the Chief Executive Officer), one with Amtrak's safety culture consultant, and one with representatives from each organization's union leadership. Engaging a diverse set of 
Table 1: Research and Interview Questions.

\begin{tabular}{|c|c|}
\hline Research Questions & Amtrak/WMATA Interview Questions \\
\hline $\begin{array}{l}\text { 1. How do Amtrak and } \\
\text { WMATA define safety } \\
\text { culture? }\end{array}$ & $\begin{array}{l}\text { - What are the various important elements of } \\
\text { an effective safety culture } \\
\text { - How do you define safety culture? }\end{array}$ \\
\hline $\begin{array}{l}\text { 2. What were the two } \\
\text { organizations trying to } \\
\text { change in their safety } \\
\text { cultures? }\end{array}$ & $\begin{array}{l}\text { - What policies and procedures were in place } \\
\text { before Amtrak and WMATA implemented } \\
\text { their new safety cultures? } \\
\text { - What prompted the focus on safety culture? }\end{array}$ \\
\hline $\begin{array}{l}\text { 3. What did the two } \\
\text { organizations do to } \\
\text { improve their safety } \\
\text { cultures? }\end{array}$ & $\begin{array}{l}\text { - What new policies and procedures character- } \\
\text { ize each organization's new safety culture } \\
\text { programs? } \\
\text { - What different roles do executives, managers, } \\
\text { and labor unions play? } \\
\text { - How did Amtrak and WMATA create organi- } \\
\text { zational buy-in? }\end{array}$ \\
\hline $\begin{array}{l}\text { 4. What are the les- } \\
\text { sons that Amtrak and } \\
\text { WMATA have learned } \\
\text { during their safety cul- } \\
\text { ture transformations? }\end{array}$ & $\begin{array}{l}\text { - What elements of both organizations' plans } \\
\text { have succeeded and which have not? } \\
\text { What can other organizations learn from Am- } \\
\text { trak's and WMATA's experiences in adopting } \\
\text { a new safety culture? }\end{array}$ \\
\hline
\end{tabular}

stakeholders yielded a comprehensive and detailed perspective of each organization's safety culture. The interviews, which were the primary data source used to develop logic models, findings, and conclusions, ranged from 30-60 minutes and were conducted in person whenever possible.

Despite the research team's efforts to create a rigorous design, there are potential threats to validity and reliability of the study's findings. One area of concern is whether the data collected were accurate. Safety is a sensitive subject for the two organizations and both organizations have been scrutinized over the issue in recent years. Therefore, Amtrak and WMATA personnel may have had incentive to report overly positive results, especially if they thought the report could become public knowledge. The research team tried to minimize this threat by emphasizing that respondents' names would not be used without consent. Accidental misrepresentation may also have occurred if interviewees remembered facts or events incorrectly. Finally, there is a social desirability factor that may have caused interviewees to give responses that would please management or the research team. The research team included both management and employee perspectives in order to guard against obtaining unbalanced feedback. Other concerns result from the study's timing and limited generalizability. This study began approximately one year into the implementation of safety initiatives in both organizations, so researchers had to rely on study subjects' description of conditions before the safety initiatives were implemented. Additionally, the team collected data over a period of approximately six months. This long time period means that the data do not provide a snapshot in time, but rather an ongoing window into a changing landscape. Consequently, what was true in earlier interviews may not have held true in later interviews. While the research team could not eliminate these possibilities, they attempted to ask broad questions so that pertinent information about events affecting safety would become evident. 
Another concern is that the research team was unable to gather data on the actual effects of new safety policies (e.g., a measured shift in employee attitude or a reduction in accidents), but instead learned only about the perceived effects. Finally, the findings are very specific to the studied organizations. While the key findings from each organization may provide other rail transportation organizations with insight into how to redevelop safety cultures, organizations need to think critically about how they compare with Amtrak and WMATA before determining which practices to adopt.

\section{Case Study 1: Amtrak}

Since its founding, Amtrak has made safety its chief foundational corporate value. Specifically, Amtrak aims "to reduce the risk of harm for our employees and our customers in everything that we do" (Amtrak 2010). Furthermore, making Amtrak "the safest passenger railroad in America" is the first of the company's five strategic goals to achieve its mission of providing efficient and effective intercity rail service (Amtrak 2010).

Amtrak has several layers of oversight. External oversight comes from the Federal Railroad Administration (FRA) and the Occupational Safety and Health Administration, while internal oversight comes from Amtrak's Environmental Health and Safety department, including a working group focused on safety. The safety working group creates and monitors programs and policies to protect the safety of both customers and employees. In addition, the group ensures Amtrak's compliance with relevant Occupational Safety and Health Administration and FRA regulations. Working group staff members execute essential functions like investigating major accidents and incidents, managing Amtrak's Safety Information System database, creating training standards and courses, and managing comprehensive safety evaluations or audits to certify compliance with regulatory standards (Amtrak 2007).

The Safety working group also supports the corps of field safety officers assigned to Amtrak's transportation, mechanical, and engineering units. Field safety officers enforce existing safety programs, identify and reduce safety hazards, and develop local safety policies and training initiatives. In addition, local managers implement and are accountable for all facets of the safety program, including enforcing safety rules within their units, reporting accidents and defects, and creating employee safety committees (Amtrak 2007).

The Environmental Health and Safety department oversees Amtrak's system-wide safety initiative, the System Safety Program. Its purpose is to present an all-inclusive framework for the company's safety strategy. To this end, the program documents incidents and safety initiatives, establishes an agenda for implementing policy to achieve safety goals, collaborates with various safety stakeholders, and ensures compliance with all laws and regulations (Amtrak 2007).

The Environmental Health and Safety department is currently overseeing the implementation of two complementary safety initiatives to help advance Amtrak's safety strategy. The first, Positive Train Control, uses technology to enforce speed limits and prevent collisions; Amtrak is extending this system to its entire rail network. The second major initiative, Safe-2-Safer, focuses on changing the culture of Amtrak and is described in more detail below. One measure of Amtrak's commitment to its new safety culture is the level of funding that it has devoted to these programs, which is illustrated in Table 2. Amtrak has devoted more than $\$ 28$ million to its safety culture initiative, with the bulk of this funding coming in Fiscal Years 2010 and 2011. Amtrak's Safety Audit Program reports on the status of safety compliance with both the company's own policies and those of outside regulators (Amtrak 
Table 2: Amtrak Safety Culture Funding FY2010 - FY2014.

\begin{tabular}{|l|l|l|l|l|l|l|}
\cline { 2 - 7 } \multicolumn{1}{c|}{} & FY2010 & FY2011 & FY2012 & FY2013 & FY2014 & Total \\
\hline Safety Culture Costs & $\$ 11.0 \mathrm{~m}$ & $\$ 9.7 \mathrm{~m}$ & $\$ 7.1$ & $\$ 0.5 \mathrm{~m}$ & $\$ 0.5 \mathrm{~m}$ & $\$ 28.7 \mathrm{~m}$ \\
\hline Projected Savings & - & $\$ 0.7 \mathrm{~m}$ & $\$ 2.0 \mathrm{~m}$ & $\$ 2.3 \mathrm{~m}$ & $\$ 2.8 \mathrm{~m}$ & $\$ 7.8 \mathrm{~m}$ \\
& & & & & & \\
\hline Net & $\$ 11.0 \mathrm{~m}$ & $\$ 9.0 \mathrm{~m}$ & $\$ 5.1 \mathrm{~m}$ & $(\$ 1.9 \mathrm{~m})$ & $(\$ 2.3 \mathrm{~m})$ & $\$ 20.9 \mathrm{~m}$ \\
\hline
\end{tabular}

2009). These reports are not intended to substitute for extensive safety evaluations, but they do illustrate how Amtrak is promoting a safety culture throughout the system. Between fiscal years 2004 and 2009, Amtrak achieved a dramatic decrease in the number of reportable injuries per year, as shown in Table 3 .

\section{Definition of Safety Culture}

Amtrak interviewees indicated that safety culture was the aggregate result of safety practices, behaviors, and values at all levels of the organization. Rather than identifying technical issues, each interviewee described safety culture as an attitude that is self-perpetuating and generates consistently improving safety outcomes. According to CEO Joe Boardman, safety culture is "all of the things you can't touch at Amtrak, all the ways that we operate and interact with each other. It's the rules; it's the process of how we enforce those rules, and how people get their work done" (Interview with Joseph Boardman 2011). Furthermore, the interviews revealed that Amtrak employees view factors like teamwork and unity of purpose as essential to a successful safety culture. This definition closely aligns with the definition used by the Department of Transportation.

An effective safety culture requires that employees at every level feel informed and invested in the goal. An
Amtrak supervisor explained that this new culture instituted a paradigm shift for both management and line employees. No longer was one person in charge of overseeing safety. Rather, employee safety became everyone's responsibility. Line employees work on the trains or tracks. They often perform dangerous jobs and are thus more directly responsible for safety. This shift emphasizes that employee safety is a fundamental piece of Amtrak's safety culture. Interviewees expressed that everyone, from the most senior executives to the newest track workers, must be included in developing and adopting the safety culture to infuse the degree of ownership required to sustain it over the long term.

Interviewees agreed that the basic unifying mission of each employee is to ensure the safe behaviors of his or her colleagues. To this point, a consultant involved in creating Amtrak's safety program said that excellent safety can only be achieved when an organization establishes a culture in which people look out for each other in order to minimize risky behavior. He argued that achieving this level of buyin and cooperation requires all employees to adopt habits of transparency to honestly and accurately communicate safety information and feedback to superiors, peers, and subordinates. Without this free flow of dialogue, an organization is likely to remain mired in a culture of ignorance and

Table 3: Annual Amtrak Reportable Injuries FY2004 - FY2009.

\begin{tabular}{|l|l|l|l|l|l|l|}
\cline { 2 - 7 } \multicolumn{1}{c|}{} & FY2004 & FY2005 & FY2006 & FY2007 & FY2008 & FY2009 \\
\hline $\begin{array}{l}\text { Total Reportable } \\
\text { Injuries }\end{array}$ & 891 & 709 & 614 & 453 & 552 & 447 \\
\hline
\end{tabular}


disunity regarding the mission of safety.

\section{Conditions Prior to Safety Culture Initiative}

The research team identified three main areas Amtrak sought to improve through its new safety culture program: the antagonistic relationship between management and labor, a culture of blame, and lack of transparency.

Prior to Mr. Boardman's arrival at Amtrak as CEO in 2008, the railroad's unions had lacked a contract for eight years, which was emblematic of the tension that existed between management and labor. In one interview, a union leader described a "deep-seated mistrust of management that had built up over generations" (Interview with Union Leader 2011). A second union official called management's attitude towards labor "militaristic" prior to Mr. Boardman's tenure. This official felt that Amtrak management treated union laborers without respect and allowed them little meaningful input into corporate decisions. He claimed that this attitude extended to a disregard for workers' safety, resulting in hazards such as sleep deprivation and excessive exposure to noise and vibration. The safety consultant working with Amtrak noted that employees loved working in the railroad industry, but disliked Amtrak management. Despite its pervasiveness, this animosity was still a surprise to most in management. The mistrust had existed for so long that winning support for the new safety initiative from Amtrak's 15 labor unions proved challenging. Management has since built up enough credibility with labor that 13 of the 15 unions have agreed to participate in all aspects of Amtrak's safety culture initiative.

The tension between management and labor manifested itself through a culture of blame with respect to safety violations. Rather than working together to examine and fix problems or crises, management and labor treated safety incidents as offenses meriting punishment. This sys- tem did little to improve safety conditions; instead, it greatly diminished both trust and safety outcomes throughout the system. According to Mr. Boardman, Amtrak had "a culture of blame...because there are so many rules, when an employee had an accident here, as with most railroads, you could find a rule they violated, a safety rule or otherwise, and discipline them for having the accident, being injured" (Interview with Joseph Boardman 2011). In describing Amtrak's old safety culture, one senior official said that charging employees with rule violations when they were injured prevented Amtrak from identifying and resolving the root cause of the incident. This approach further alienated employees from management. The consensus view among the interviewees was that this culture of blame posed an enormous obstacle to improving the company's safety culture.

One significant byproduct of the culture of blame was a lack of candor in accurately reporting safety incidents. Workers felt little incentive to report incidents since they expected that management would punish them for having creating the hazard. This attitude extended to middle managers who were fearful of communicating incident reports to their superiors for the same reason. As a result, the suppression of safety reporting became endemic within the company. Amtrak's safety consultant explained that "if there was an injury, the negative consequences were so significant that you wouldn't want to report. So if you got injured and you came to me, I'm your manager, it was 'Okay we're going to do an investigation. Was this guy on duty? Was it an off-duty thing, a false report?' Then it becomes a big investigation into you" (Interview with Safety Consultant 2011).

Consequently, some incidents and hazards would go unaddressed and remained threats to both employees and passengers. Amtrak's safety record prior to implementing its new safety strategy was illusory: the official numbers never told the full story since underreporting was 
so prevalent. In sum, the safety reporting dynamic at Amtrak resulted mainly in punitive action and suppression, rather than transparency and sustained improvement.

\section{Strategies to Improve Safety Culture}

To assess current practices and begin the change process, Amtrak first hired a safety consulting firm, Behavioral Science Technology (BST), for a three-year contract involving 45 outside specialists. Amtrak and BST administered a companywide survey, the Organizational Cultural Diagnostic Instrument. The survey measured employee attitudes toward Amtrak across nine fields that BST determined to be strongly correlated with safety. Examples include management credibility, upward communication, organizational fairness, and the value the organization places on safety. There were approximately 10,000 respondents to the 95-question survey. To add detail to the survey data, Amtrak and BST conducted 82 focus groups involving a total of roughly 800 employees. The focus groups intended to gauge whether employees were adequately following safety guidelines on the job.

Amtrak and BST used this information to develop the Safe-2-Safer approach to transform the railroad's safety culture on three organizational levels and augment the capabilities of leadership and management. First, senior executives began a training process that emphasized how to lead a safe organization. Each executive worked with a personal coach from BST and completed a $360^{\circ}$ Leadership Diagnostic Instrument assessment focusing on whether his or her leadership style was conducive to a safe environment. Based on assessment results, each executive set goals regarding how he or she would change personal behaviors in order to promote safety. Amtrak and BST refer to these goals as a Safety Action Plan. The executive then entered the plan into BST's feedback database, which monitors each executive's progress using information from executives, managers, and employees. Managers also took the leadership assessment and tracked their progress in the database. Each of the 2,100 Amtrak managers also received training in four leadership modules on areas in which Amtrak scored poorly in the assessment: foundations, credibility, accountability, and feedback and recognition. To garner participation from line employees, Amtrak and BST created steering committees of union-nominated workers, representing the company's different regions and specialties. Amtrak management had no role in selecting participants. The committees' goal was to establish, reinforce, and train rail workers in sound safety practices in each of their respective specialties.

Once workers established a steering committee and determined what safe and unsafe behaviors looked like, the next phase was the peer-to-peer safety observation system. The steering committees deployed trained observers to evaluate their fellow workers and provide feedback on their safety performance. Observers emphasized positive comments, no matter how minor. The three essential tenets of the observation program were that it was non-punitive, anonymous, and voluntary for employees to participate. An observer will alert an employee that he or she will be assessed; following the observation, the observer reports to the employee some of the specific positive behaviors he or she viewed. The goal was for observers to evaluate each worker on a monthly basis. The steering committees then deliver these anonymous reports to management for analysis and potential policy adjustments. Due to the popularity of these observations, more employees started undergoing observer training so that they too could conduct the peer-to-peer observations. Amtrak also undertook several activities outside of the Safe-2-Safer program. To repair the relationship with the unions, Amtrak senior executives established regular meetings with union 
112 Developing Safety Cultures in Amtrak and WMATA

leaders. These meetings gave the union chairmen a chance to express their concerns and discuss potential problems, and contributed to the unions and Amtrak reaching an agreement on a new contract.

\section{Amtrak Logic Model}

A logic model graphically depicts an organization's theory of how inputs and activities should lead to desired goals. Based on interviews and document reviews, the researchers determined that two separate logic models would best represent Amtrak's safety culture improvement process. One logic model details the changes in Amtrak independent of the Safe-2-Safer approach. The second depicts the Safe-2-Safer process that Amtrak developed with BST.

Although these logic models imply two independent processes, the theory of change in these models overlap in the later stages of the programs. Consequently, these logic models should not be viewed as two discrete and linear streams, but rather as two branches of the same organizational tree which often lead back to each other and advance in the same direction.

Figure 1 demonstrates Amtrak's safety culture development independent of the Safe-2-Safer program. Amtrak conducted several new activities and continued existing activities to enhance safety culture. Among the continuing activities were maintaining standard safety practices (e.g., stopping a train fully before boarding or disembarking,) and complying with the FRA's safety standards. New activities include Positive Train Control, and regular meetings with union leaders. Figure 2 details Amtrak's final significant activity is the Safe-2-Safer process.

One short-term outcome, more accurate injury reporting, is complex to measure. Notably, the increased accuracy in injury reporting is expected to precede the actual decrease in injury claims, meaning that the injury rate will initially rise before changes to safety processes lead to a reduction in incidents. Oversight agencies and other stakeholders must be willing to accept this temporary increase in incident rates. Following the improved accuracy of incident reports, the first long-term outcome is to achieve a sustained reduction in the number of accidents, injuries, and fatalities. When incident reporting is accurate, Amtrak can address the causes so that preventable incidents no longer occur. The second outcome is visible and sustained leadership commitment, management buy-in, and employee participation in the safety processes. This outcome requires that all levels of the organization adopt the safety processes and culture, and that all employees feel ownership of these changes. The final long-term outcome is that Amtrak is a more collaborative organization, indicating a broader institutional change.

To explain the environment for the changes that Amtrak sought, the research team separated the contextual factors into two categories. The first category describes the early conditions that Amtrak encountered when it started the safety culture process. The second enumerates ongoing contextual factors that are beyond Amtrak's control, including FRA oversight, congressional funding, and disparate regional rail regulations.

The second logic model focuses on the Safe-2-Safer process. Three distinct groups are involved with Safe-2-Safer's activities: senior executives, management, and railway employees. The logic model follows the activities, outputs, and outcomes separately for each group. Safe-2-Safer's outcomes for senior executives are to elevate safety to Amtrak's highest priority and to continuously improve executives' leadership skills. The managers' and employees' outcomes reinforce each other, thus establishing a virtuous circle of safety outcomes. The long-term outcomes are similar to those depicted in Figure 1. The activities taken by Amtrak independently and through the Safe-2-Safer process will bolster each other to achieve the overall 
impact, that Amtrak develops a sustained culture of safety. This impact means that the organization continues to report incidents accurately and without retribution, seeks ways to actively prevent them, and maintains the collaborative culture that the company develops during this process.

\section{Lessons Learned During Safety Culture Transformation}

\section{Safety Culture is Organizational Culture}

During the Amtrak change process, safety became the avenue through which the organization experienced broader cultural change. Amtrak sought to become a more collaborative organization by changing its safety culture. Safety was something the organization could unify around because everyone benefits from feeling safe at work. Amtrak realized from the beginning of the change process that safety culture was not separate from the broader organizational culture. In fact, Amtrak recognized that to divide organizational culture from safety culture would detract from the idea that all employees are responsible for safety at all times. As Mr. Boardman stated, "Safety is owned by everyone. You don't have a VP for safety and that person owns it - no way" (Interview with Joseph Boardman 2011). As part of the Safe-2-Safer process, one outcome is for managers to become more interactive, responsive, credible, and accountable. The key point is that these outcomes not only enhance safety, but also help managers gain credibility with their employees in all areas. Amtrak believes it can achieve safety outcomes by establishing a more collaborative organizational culture.

\section{Change Begins with Top Leaders}

Mr. Boardman was the driving force behind implementing the safety culture transformation. Multiple interviewees noted that he became personally involved with the process and was the organization's champion of the change. Several managers emphasized that transforma- tional change must start at the top of the organization with the CEO's full support. One Amtrak manager explained, "You have to have a CEO and executive committee and management team that is committed and has fully bought into the benefits... You have to be willing to do everything that you're asking your employees and managers to do in terms of your values and ways that you talk, care about, and interact with people" (Interview with an Amtrak Manager 2011). Furthermore, union leaders were emphatic in their praise for how drastically Mr. Boardman has transformed the safety culture at Amtrak. They made a particular point of noting that Mr. Boardman was far more sincere in his commitment to changing the railroad's safety culture than his predecessors.

The CEO's primary role in the transformation process was to fundamentally change Amtrak's core values. To truly alter the organization's values, Mr. Boardman mandated that leaders practice respect and humility, which he defined as inclusion, collegiality, and backing words with actions. Focusing on how leaders approach their work and their employees was intended to create a culture in which people could trust and express concerns to their managers without fear of reprisal.

As the lead proponent for change, Mr. Boardman accepted significant professional risk by staking his name and reputation on such a lengthy and expensive process. In addition to the commitment of considerable resources, another risk that Mr. Boardman accepted was that injury rates could rise after the initial program implementation because of honest incident reporting. Mr. Boardman had to convince the Board of Directors and other Amtrak stakeholders that Safe-2-Safer was worthwhile, despite the appearance of increasing incidents. Interviewees thought that without Mr. Boardman's full support and willingness to accept risk, Safe-2-Safer would probably not have been implemented. 
Figure 1: Amtrak's Safety Culture Development Logic Model.

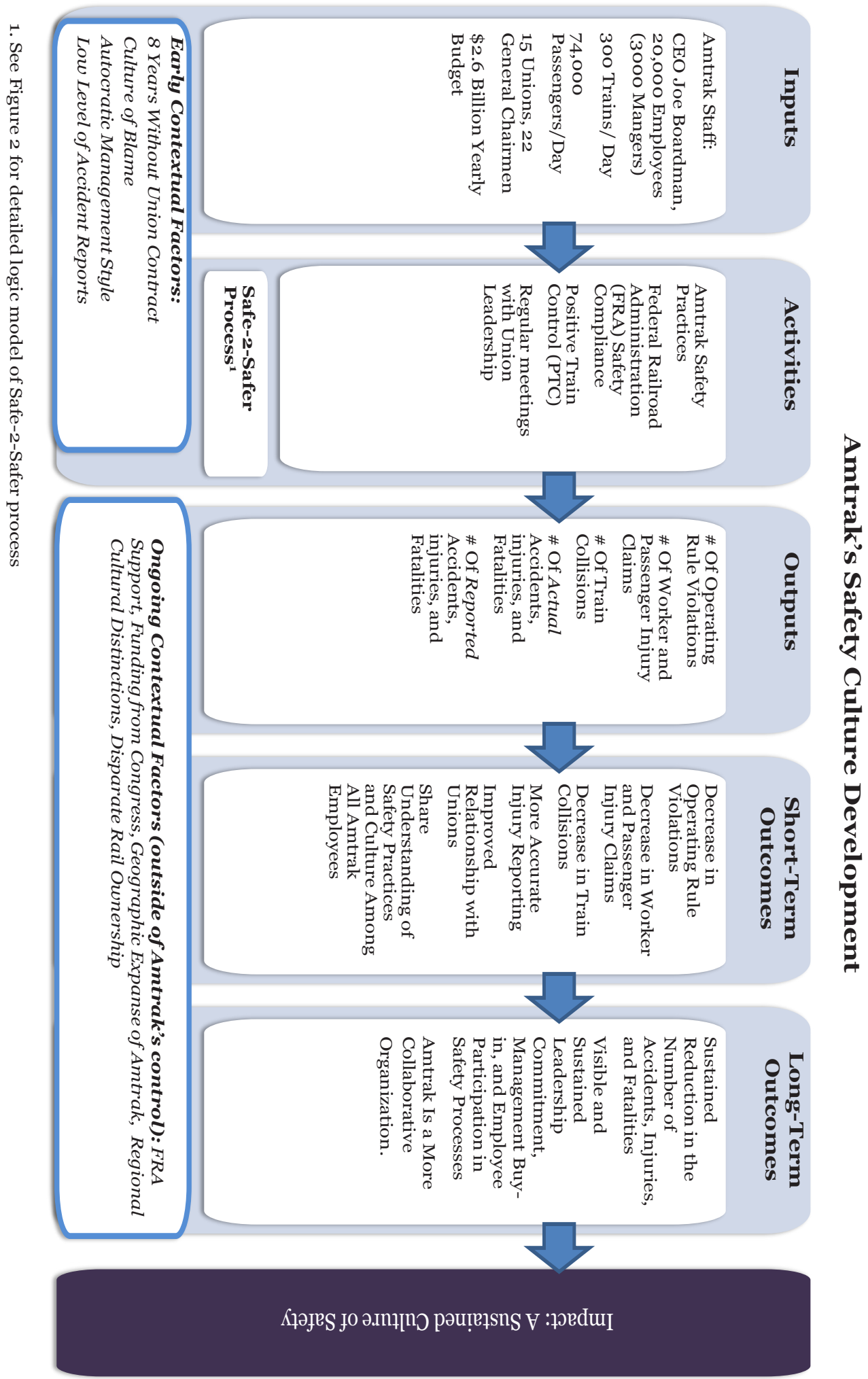


Figure 2: Amtrak's Safety Culture Development: Safe-2-Safer Process Logic Model.

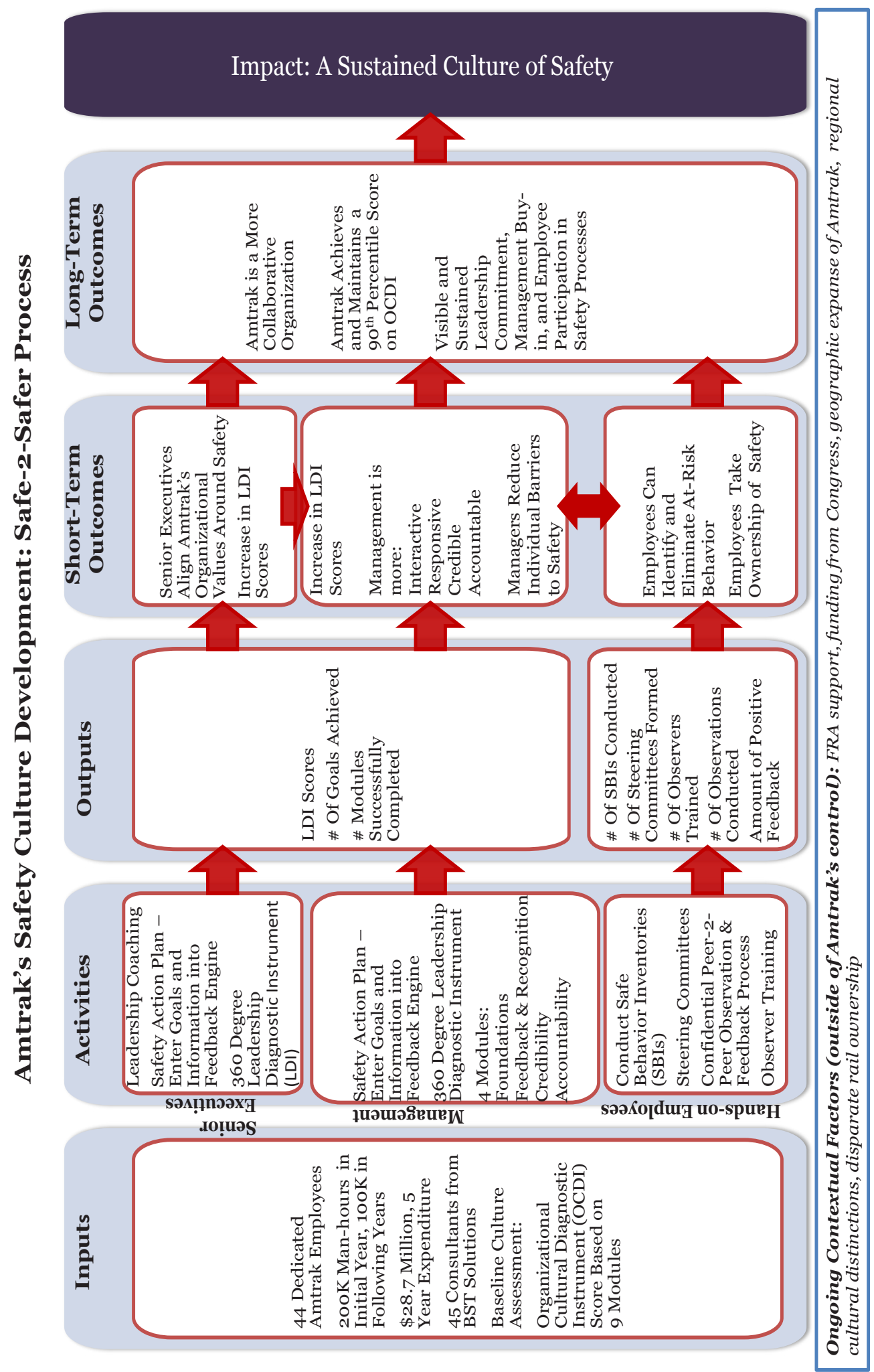


Ensure Accurate Incident Reporting

When Amtrak began the Safe2-Safer process, top leadership realized that suppressing injury and accident reporting was common throughout the organization. Amtrak's attitude was not concern for the employee's safety, but rather finding fault with the employee. As a result, employees would habitually underreport accidents and injuries. To encourage honest incident reporting, Amtrak separated safety performance (the number of accidents and injuries) from supervisors' job performance reports. The old system had provided incentives (e.g., bonuses and promotions,) for supervisors that had the side effect of encouraging dishonest injury reporting. Once Amtrak separated safety performance from job performance and supervisors no longer concentrated on finding blame, its injury numbers surged as employees felt comfortable reporting injuries. Without an accurate understanding of Amtrak's safety performance, the change process would not have been possible.

\section{Invest Line Employees in Safety Process}

Traditionally, safety was viewed as management's responsibility. Now, Amtrak believed that management and rail employees were equally responsible for safety. A prime example of this effort was the establishment of the independent, employee-led safety steering committees. As part of their work, the committees established inventories of safe behaviors which they communicated to the workforce. Often, the committee members become the vocal proponents of the very change management hopes to achieve so that, as Amtrak's BST consultant asserted, acting safely becomes "how we do things around here." The safety consultant noted one of Amtrak's major outcomes: "You've got to get to a place where people own safety at the same level Joe Boardman owns safety, at every level of the organization" (Interview with Safety Consultant 2011). Once employees have this ownership, they cease to think about safety as the dissemination of rules by management fiat. Rather, employees act safely because they have a stake in changing the culture.

\section{Eliminate Blame-Oriented Culture}

Prior to the Safe-2-Safer process, a combative relationship existed between Amtrak management and employees. Instead of garnering commitment from employees, this system of rules led employees to adopt an "us against them" attitude toward to management. Amtrak realized that stringently disciplining employees could work for a period of time, but eventually employees became defensive and uncooperative. As the BST safety consultant stated, "Until an organization is set up so the culture makes it okay for everyone to really look out for each other's safety, and it's not about getting you, you'll never achieve safety excellence" (Interview with Safety Consultant 2011). Thus, to invest everyone in the safety process, Amtrak needed to re-establish trust between employees and managers. Eliminating a blame-oriented culture did not mean that employees were not accountable for rule violations. The emphasis for Amtrak mangers was now on holding employees accountable for their unsafe actions by coaching them toward the correct behavior. Amtrak understands that not all employees will display "organizational citizenship," and that these intractable employees may not be coachable. An executive explained that the company resolved to hold everyone, managers and employees, accountable for living up to the company's values and standards. When people fail to do so, Amtrak may have to remove a manager, or more rarely, an employee. However, the primary method of accountability was now positive feedback. This represented a fundamental shift in Amtrak's organizational culture.

\section{Establish Trusted Feedback Mechanisms}

Part of Safe-2-Safer's observation and feedback process required employ- 
ees to give and receive positive feedback. The peer-to-peer process allowed employees to voluntarily observe coworkers who were conducting risky jobs. No names were recorded and no discipline could result from the observation session. If an observer saw an employee putting him or herself in imminent danger, the observer had a responsibility to stop the action. Importantly, however, blame was not assigned. Instead, the observer and employee began a dialogue to determine the root cause of the unsafe action. Once these causes were identified, management acts to eliminate or mitigate any barriers to safety. Barriers could include anything from faulty equipment to an unrealistic requirement imposed by management. The goal of the observation and feedback process was to provide the employee with primarily positive feedback and to define what constitutes safe work.

\section{Define Safe Work}

In order to be able to provide positive feedback, employees must first develop an understanding of what safe behavior looks like. Traditionally, employees had received overwhelmingly negative feedback from mangers and did not understand what Amtrak considered to be correct behavior. The BST safety consultant noted, "Most organizations don't focus on positive behavior, only negative, when in reality 95 to 98 percent of employee behavior is safe. The problem is employees don't get any feedback and are unsure if they should continue acting safely" (Interview with Safety Consultant 2011). As part of the process, safety steering committees established Safe Behavior Inventories, which aggregate and document safety practices. These inventories created a base of institutional knowledge for Amtrak employees to learn what constitutes safe work.

\section{Focus on Safety Processes}

A major shift in Amtrak's approach to safety was to manage safety processes, not just outcomes. Prior to the change initiative, Amtrak managers had focused overwhelmingly on whether an unsafe incident occurred, not whether they were appropriately managing safe behaviors. For example, if a train operator routinely ran his or her train ten miles per hour over the speed limit, this constitutes unsafe behavior. However, prior to the change process, if the train operator's behavior did not cause an accident, the action would not be identified as unsafe. Therefore, it was likely that the train operator would continue to operate unsafely. Also, prior to the transformation process, if an Amtrak employee was injured on the job, it often triggered a disciplinary review. The manager would focus on the outcome of the injury and not on the behavior that caused the accident. Addressing this unsafe behavior is the difference between managing processes, which can prevent an incident, and managing outcomes, which can only react to an event.

\section{Foster Transparent Communication}

Amtrak interviewees agreed that fostering open, transparent lines of communication within the company, both vertically (between different levels of employees) and horizontally (across employees in the same level), is essential in any organization attempting to improve safety culture. Interviewees interpreted this communication in various ways. One Amtrak executive recalled how important it was for leadership to constantly and vigorously proclaim the successes of the program. The key, according to one Amtrak executive, was removing punitive repercussions from safety observations and reporting. This change freed lowerlevel workers to deliver accurate safety information up the company's chain of command. Similarly, the peer-to-peer observation and feedback model facilitated productive interactions between coworkers to improve safety behaviors. The need for effective communication is the driving purpose behind the Safe-2-Safer processes focusing on leadership skills. 
As noted earlier, the organization had a dearth of forthright communication before it undertook its safety transformation. Amtrak's progress in surmounting the years of dysfunction that cultivated this poor communication has been one of the company's singular achievements. Amtrak learned that without better communication, it would be unlikely to secure either sufficient employee buy-in or accurate safety reporting within all areas of the company. Early in the safety transformation process, it became clear that Amtrak faced considerable challenges to remaking its safety culture. By incorporating safety into organizational culture, establishing buy-in from employees at all levels, defining and emphasizing safe practices, and creating open and honest communication free from repercussions, Amtrak has directly addressed these challenges to transform its safety culture.

\section{Case Study 2: Washington Metropolitan Area Transit Authority}

WMATA's operations are controlled by multiple layers of management and committees. WMATA is run by a board of directors that consists of eight voting members and eight alternates; Maryland, Virginia, the District of Columbia, and the federal government appoint two people in each category. The board oversees the general manager, who in turn oversees the chief safety officer and other executive roles within the organization. Metro's current general manager, Richard Sarles, was confirmed January 27, 2011. Mr. Sarles' 40 years of transit experience includes time at Amtrak and the New Jersey Transit system.

Four agencies oversee WMATA's safety operations. One, the Tri-State Oversight Committee (TOC), is a State Safety Oversight agency consisting of the DC Department of Transportation, the Maryland Department of Transportation, and the Virginia Department of Rail and Public Transportation. This committee sets standards for and approves safety plans, investigates accidents, requires and approves corrective actions for safety failings, and reviews safety plans and their implementation at least every three years (Tri-State Oversight Committee, no date). The committee has no enforcement capabilities; the state legislature is responsible for all enforcement. WMATA is also subject to safety oversight from the Federal Transit Administration (FTA), which provides technical assistance and funding; National Transportation Safety Board (NTSB), which investigates accidents; and the American Public Transportation Association (APTA), a professional trade organization which develops a standardized rail system safety format. WMATA is also overseen by Congress, although Congress does not have the same ongoing involvement as the other oversight agencies.

\section{Safety Incidents and WMATA Response}

WMATA has had several notable safety failures, but the most serious was the 2009 Red Line Metro crash near Fort Totten Station in DC. Two trains collided, resulting in nine deaths, dozens of injuries, and \$12 million in damage (National Transportation Safety Board 2010). NTSB investigated this accident and wrote a scathing report that identified severe deficiencies in WMATA's safety culture.

NTSB found that WMATA failed to adequately identify safety concerns, distribute important safety information across the organization, and enact effective safety policies. Furthermore, NTSB stated that within WMATA there is a "general lack of importance assigned to safety management functions across the organizations" (National Transportation Safety Board 2010).

The report detailed weaknesses in WMATA's safety protocols that indicated a deficient safety culture. The report noted that "WMATA Metrorail managers placed [a low priority] on addressing malfunctions in the train control system" (National Transportation Safety Board 2010). 
The report also stated that "shortcomings in WMATA's internal communications, its recognition of hazards, its assessment of risk from those hazards, and its implementation of corrective actions are all evidence of an ineffective safety culture within the organization" (National Transportation Safety Board 2010). In addition, NTSB noted that safety oversight was inadequate. NTSB also argued that the WMATA safety officer did not have the resources or authority to identify and remedy safety issues. The report stated the TOC's oversight was ineffective and the WMATA board of directors did not adequately follow the corrective action plans from earlier TOC and FTA safety audits. In sum, NTSB identified WMATA's lack of a safety culture as the primary cause of the accident, an assessment that other officials endorsed.

Two years after the accident, many stakeholders still had concerns. Leaders of Amalgamated Transit Union (ATU) Local 689 , which represents more than 10,000 Metro employees, complain of systemic safety deficiencies. Others, however, had seen progress in WMATA's efforts to improve its safety culture. In Congressional testimony in 2011, Mr. Sarles described an incident in which "more than a dozen track workers came to his office to protest the termination of an employee who failed to properly monitor the movement of track equipment." Mr. Sarles listened to them but did not change his mind, because "we take very seriously the safety of employees." Maryland Senator Barbara Mikulski said that this encounter represented "a changing culture" (Hedgpeth 2011). The hearing also noted an increase in safety rule violations. As safety culture research shows, however, this increase may not actually represent an increase in violations, but rather an increase in the accurate reporting of violations. Overall, Mr. Sarles said that the "agency has started to turn the corner" (Hedgpeth 2011).

\section{Definition of Safety Culture}

The organization's official defini- tion of safety culture is "the product of individual and group values, attitudes, perceptions, competencies, and patterns of behavior that determine the commitment to, and the style and proficiency of, an organization's health and safety management." WMATA's chief safety officer elaborated that "safety culture must be led, not imposed" so that this process can "embed safety values in every WMATA employee so that safety is at the center of all actions and business practices." The chief safety officer expanded on the official definition to say that "safety culture is when every employee in an agency or a company believes that safety is...their primary role and responsibility" (Interview with Chief Safety Officer 2011). WMATA's definition aligns with DOT's definition, in that both emphasize shared values and behaviors, and both prioritize safety over all other goals.

Several WMATA personnel gave their own interpretations of safety culture. One superintendent explained, "It's a mindset. It's how people think and how people view safety...Safety is being able to recognize danger" (Interview with WMATA superintendent 2011). A safety trainer said that "an ideal safety culture would be employees who observe safety rules, regulations, and also employees who look out for the well-being of the individuals they work with" (Interview with Safety Trainer 2011). Importantly, both of these definitions call for people to follow both the letter and the spirit of safe behavior rules.

\section{Conditions Prior to Safety Culture Initiative}

According to interviewees, three key problems prompted WMATA to target safety culture: lack of focus on safety details, inconsistent communication, and a poor relationship between employees and managers. Because of these problems, some WMATA personnel, including the ATU Local 689 Union's chief safety officer Wayne Garland, believed an accident on the scale of the Red Line crash was inevitable. WMATA has tried 
to overcome these organizational shortcomings by developing its safety culture.

WMATA employees perceived a lack of attention to the small details of safety. A superintendent noted that many general managers concentrated on keeping trains and people moving, and relied on supervisors and managers to consider safety. He explained, "We were having little incidents that began to add up; they started getting bigger and bigger...it was embarrassing to even say that you worked for Metro" (Interview with superintendent 2011). Mr. Garland emphasized that problems stemmed from both employees and managers becoming complacent and not focusing on safety behavior, training, or equipment. He went on to explain that WMATA has tried to "discipline the problems out" of people, but that this discipline relied on antiquated procedures, including firing employees for missteps. Most importantly, he expressed that managers must believe in and respect employees in order to develop a safety culture. Managers may have been incentivized to ignore small safety concerns so that their safety numbers look good on paper, rather than attending to actual safety and providing a high-quality service to the public.

WMATA is a large organization with many departments, oversight bodies, and personnel; keeping everyone informed of the safety culture change posed a challenge. The chief safety officer described how problems likely stemmed from inconsistent communication of proper procedures, as well as the existence of different operating procedures between groups within WMATA. He noted several reasons for the poor communication. First, WMATA lacked a centralized database of information, which meant that WMATA could not efficiently track incident trends and identify problem areas. Second, the safety officers were too centralized - they were all located in the WMATA main office in downtown DC, even though the reach of the Metro train and bus system expanded into Maryland and Virginia.
Additionally, safety officers only worked standard business hours, so no one was available during nights or weekends. The poor relationship between workers and managers represented a substantial barrier to creating a strong safety culture. Line employees felt undervalued and unheard by their superiors. The chief safety officer noted, "I'm not sure if they really thought management cared about them, and I believe in a safety world, if you don't care about fellow human beings, you're doomed for failure" (Interview with Chief Safety Officer 2011). Employees felt that supervisors did not prioritize safety, and that employees could not protect themselves against unsafe situations. A safety trainer explained that many employees felt that supervisors prioritized production at the risk of compromising safety; often line employees had no recourse when told to do something unsafe. Mr. Garland reiterated this perceived divide between the employees and their managers, saying that employees would report safety issues, but those issues would go unheard.

\section{Strategies to Improve Safety Culture}

Since his appointment as general manager in January 2011, Mr. Sarles has made safety a top priority. As a superintendent explained, when Mr. Sarles and Dave Kubicek, the assistant general manager of rail service delivery, began at WMATA, "They put the brakes on and said 'We're not really concerned with how much work you guys are getting done.' Now the first priority is to make the environment a safe environment for our people" (Interview with superintendent 2011). This superintendent and others agreed that this emphasis on safety from the highest level of the organization was crucial to improving the safety culture. WMATA's senior leadership took several concrete steps to immerse themselves in safety matters. The chief safety officer met every day with the general manager to discuss safety issues. Also, WMATA 
established a Safety and Security committee within the board of directors. This committee provided a brief report to the board every month and a more thorough report every three months. The chief safety officer also gave regular briefings to the executive leadership team, of which he is a member.

WMATA improved communication with its many oversight agencies and committees. WMATA revitalized its safety committee, which meets on a monthly basis to share information. This committee was chaired by the chief safety officer and includes the general manager, the executive leadership team, union leadership, and any other stakeholders. In this meeting, safety concerns are voiced and WMATA shares statistical data on specific areas within the organization, as well as data across the entire WMATA system.

While most interviewees viewed these meetings positively, Mr. Garland said the meetings are too numerous and could take more than six months to resolve an issue. He noted that when an employee reports a problem, it is important for that problem to be addressed and for the employee to be notified of the result, but that process was impeded by too many bureaucratic layers. He explained that managers do not have authority to make changes, but instead have to take the problem to a superior.

Superintendents now also meet monthly with Mr. Sarles, Mr. Kubicek, and the Safety Department. The superintendent explained that at meetings, superintendents share what is happening in their regions and what help they may need. The superintendent said that "they tell us time and time again, 'Whatever you need, you let us know. Whatever you need to do as far as safety, you do it," showing that he believed the executives provide substantial resources and support (Interview with superintendent 2011).

WMATA also revised the safety officers' and superintendents' roles. The safety officers were now dispersed to WMATA facilities around the DC area and work staggered hours so that someone is always on call. The chief safety officer explained, "Our safety officers....all have areas of responsibility that's theirs. [They] basically own that area to assist with safety. Because so often in my years, safety folks have said, 'It's not my responsibility, Operations owns that.' And we say to them, 'No, you need to help, you need to guide them, because your performance is going to be based on their records, their rates" (Interview with chief safety officer 2011). This shift speaks to the heart of an effective safety culture, in which everyone should feel responsible for ensuring safe conditions.

A superintendent reiterated that safety was now tied to performance evaluations. He explained, "In our performance evaluations...the goal is to reduce the [incident] rates from the year before incrementally until it's reduced to nothing." When asked what happens if safety goals are not met, he said, "I haven't seen that yet. But it is where a discussion comes up where your manager has the opportunity to focus on performance. In our evaluations, it's tied to raises, money. If I don't do well, I don't get extra money. And it could affect my promotion as well" (Interview with superintendent 2011). While this practice appears logical, some safety culture specialists argue that tying performance reviews to safety encourages underreporting of incidents. Also, some interviewees believe tracking safety officers' and superintendents' safety statistics provides a disincentive to report safety incidents. The union representative argued, "You're not going to get a manager who's going to report accurately a monthly safety curriculum. What they did when [the previous general manager] Catoe came in, they made all managers at-will employees...They just said, 'We need you to get the numbers down.' How you get the numbers down, they couldn't care less. They're not going to give you an accurate count of any safety procedure or any safety curriculum that's at my location if it's going to get me fired" (Inter- 
view with WMATA Union Leader 2011). However, the superintendent believes that underreporting is minimized because employees record all incidents, and supervisors are required to log all incidents in a system that does not allow their superiors to remove reports. WMATA believes this system will promote accurate reporting.

To ensure that all employees know the safety rules, WMATA instituted a Roadway Worker Protection Training program. This program is required for all employees who work on the roadway (defined as anything on the tracks, or between the gates along the tracks). Employees can earn one of four levels of training classifications depending on the requirements of their job. Since September 2010, 4,300 employees have been certified in the new safety training. Unlike the previous training system, which employees only completed once, this training has to be renewed annually. Some employees resisted this training, primarily because they doubted that WMATA's change would endure. To reassure them, the trainer explains that "Richard Sarles has taken training, the deputy and chief safety officers took training, upper level management have all taken training, and they didn't just get condensed training, they went through everything everyone else had to go through" (Interview with Safety Trainer 2011). With sponsorship from FTA, WMATA has also partnered with the Transportation Safety Institute to offer other topic-specific safety courses to staff from WMATA and other transit agencies.

WMATA instituted several measures to ensure that employees follow the procedures they learned in safety training. The 80 safety officers were expected to complete all levels of safety training, and then periodically go on the roadway to see if workers are following the rules. The training instructors also went to the roadways to hear and address people's safety concerns.

WMATA has taken other steps to communicate the safety message to employees and to involve them in reform- ing the safety culture. At the beginning of the push to improve its safety culture, WMATA hired a consultant to survey its entire workforce. To encourage employee participation, WMATA paid them for 30 minutes of time and gave a prize to one out of every 1,000 who completed the survey, resulting in a 93 percent participation rate. According to the chief safety officer, the survey asked questions like: "How do you feel about your immediate supervisor? How do you feel about the Safety Department? Whom do you [approach] to report a safety concern?" Data were aggregated and shared with the board of directors and departmental safety committees. This survey provided WMATA with a baseline understanding of employee sentiment toward the organization.

WMATA had since acted to communicate the importance of safety to employees, to provide employees with more methods to report safety concerns, and to rectify employee safety violations as they arise. To convey that safety is a priority, WMATA incorporated safety into its mission statement and regularly posted bulletins and briefings that warn staff of safety concerns and remind them of safety procedures. Despite these steps, Mr. Garland noted that WMATA still lacks a policy for reporting an incident to staff on the day it occurs, so employees may not be aware of problems in real time. WMATA developed several ways for employees to report safety concerns. WMATA established a whistleblower phone hotline and a website that allows employees to report safety concerns. The Safety Department investigates all concerns. These reporting methods have been advertised to employees through signs posted around the WMATA offices and by the safety trainers. The safety officer explained "We do it in house; it's confidential....We do not share the hotline log - it is one of the things technology has built for us, who is inputted, we restrict who has access to see it.... I'm not saying there's a few of us who have to see what 
that is, but there's never any intent for retaliation" (Interview with Chief Safety Officer 2011). While the chief safety officer and trainer both emphasized that people could anonymously report safety concerns, the chief safety officer's statement implied that some personally identifiable information of callers may be available.

For immediate safety problems, WMATA established the "Good Faith Challenge." A worker can initiate this procedure if he believes that someone's safety is compromised. Any time an employee believes that there is a threat to safety, he can stop work until the area is brought into compliance. If the issue is not resolved to the worker's satisfaction, it will then be referred to a supervisor, who must resolve the problem before work resumes. This practice empowers employees to immediately avoid or fix problems that they believe are imminently dangerous.

WMATA developed several ways to address violations that occur when employees do not follow proper safety procedures. If safety officers or safety trainers see a violation, they talk to the roadway worker in charge of safety and to the supervisor. If the roadway worker in charge does not understand how to do the work safely, the trainer or officer may call a Good Faith Challenge and send the roadway worker back to safety training. Supervisors are responsible for disciplining any employees found in violation of safety rules.

Additionally, all superintendents were required to conduct monthly safety meetings with their employees. WMATA had a database in which superintendents record the number of minutes spent talking to an employee about safety. A superintendent explained, "You go to the employee and tell them what you observed and help them recognize the danger of the safety aspect of it. And then you come up with a solution" (Interview with superintendent 2011). This practice is intended to acknowledge positive behavior by telling people what they are doing right in addition to identifying safety concerns. Most data are anonymous so that employees do not feel like they are being targeted. Superintendents are required to conduct at least 90 minutes of conversations each month.

Throughout these interviews, WMATA representatives expressed that they want to avoid a culture of finding blame and move toward a culture of learning and improving. To focus on learning, WMATA moved toward a close-call reporting system similar to Amtrak's. An employee could report if he or she was nearly in an accident or commits a safety violation, then the problem could be resolved without retaliation. However, the WMATA chief safety officer emphasized repeatedly that avoiding a culture of blame is not the same as avoiding a culture of responsibility. Specifically, he cited what he calls the three Es: engineering, education, and enforcement. He explained, "First off, you want to engineer out all your hazards. If you can't engineer them out, you want to educate folks and provide them with proper protective equipment, and then if they don't do what they're supposed to do, then you enforce... Make sure you're following the rules, but if you don't and we catch you, there's going to be ramifications" (Interview with Chief Safety Officer 2011). To reinforce positive behavior, WMATA holds events to recognize employees with exemplary safety performance (e.g., reaching different mileage points without an incident).

WMATA established new means of sharing information with employees. WMATA rewrote some of its rulebooks and manuals. Mr. Garland believes these manuals and trainings have been helpful but still fail to remedy some vital issues, and that employees need to be recertified using modern technology and techniques. To track its progress, WMATA developed a database that collects safety information and a dashboard that displays key data in an easily digestible format. Information in the database includes calls to the safety hotline, whether these concerns have been addressed, and how long they 
have been open or how much time has been dedicated to closing the call. This database is part of an effort to develop a system to track safety statistics and identify problem areas. To communicate information from this database, WMATA displays information in the reception area of the Safety Department as well as in the main lobby of the WMATA building.

\section{WMATA Logic Model}

A single logic model (Figure 3) depicts WMATA's three streams of activities. The streams are Agency Oversight, which consists of the agencies that hold WMATA accountable; Executive and Manager Actions, which include the activities of WMATA's higher organizational levels; and Employee Involvement, which is comprised of employees' direct involvement and ownership over safety.

Agency Oversight activities refers to actions by the Tri-State Oversight Committee, the FRA, NTSB, Congress, and APTA, which are empowered to identify problems and make recommendations. WMATA's short-term outcome with regard to these oversight agencies was to meet all of their safety recommendations and to report back to them frequently.

WMATA's executives and managers were involved in a number of activities to improve safety culture. WMATA executives' and managers' short-term goals were to reduce the number of hazards, to achieve a state of good repair, and to establish clear and consistent communication throughout the organization.

Finally, WMATA directly engages employees in improving safety. For example, WMATA developed the "Champions of Safety" dinner to recognize employees' consistent safe behavior. Desired outputs of these activities include the ratio of incidents reported to actual incidents, which would be difficult to measure due to potential underreporting. The goal of the various reporting mechanisms was to ensure complete and accurate reporting. These activities should produce a number of short-term goals: all employees are trained in the correct safety procedures, WMATA maintains a climate that welcomes the reporting of concerns, and employees accurately report incidents and concerns.

The activities at all the levels build toward several long-term goals, which should ultimately work in concert to reach the overarching longterm impact, that WMATA establishes and sustains a culture of safety.

All WMATA activities take place against a backdrop of contextual factors that are beyond its control but influence its operations. These include funding levels, political conditions, and WMATA's image in the media and among the public.

\section{Lessons Learned During Safety Culture Transformation}

\section{Leaders Must Support Transformation}

Interviewees at several levels emphasized that WMATA's general manager actively supported the safety culture development process. The chief safety officer said that Mr. Sarles will not compromise safety despite budget concerns. Most interviewees agreed that while buy-in at all levels was important, the full backing of toplevel leadership was essential to ensure that resources are devoted to the promotion of safety culture and to reassure people that these changes are real and lasting.

\section{Increase Transparency and Flow of Information}

WMATA facilitated the flow of information across the organization to foster cooperation and improve WMATA's ability to identify and respond to safety concerns. WMATA's steps to increase transparency include holding open monthly safety meetings, displaying safety statistics, and posting bulletins about possible safety hazards and lessons learned from preventable incidents. Interviewees shared different views about the importance of transparency. The chief safety officer explained, "We're sharing information. We're not 
Figure 3: WMATA Safety Culture Development Logic Model.

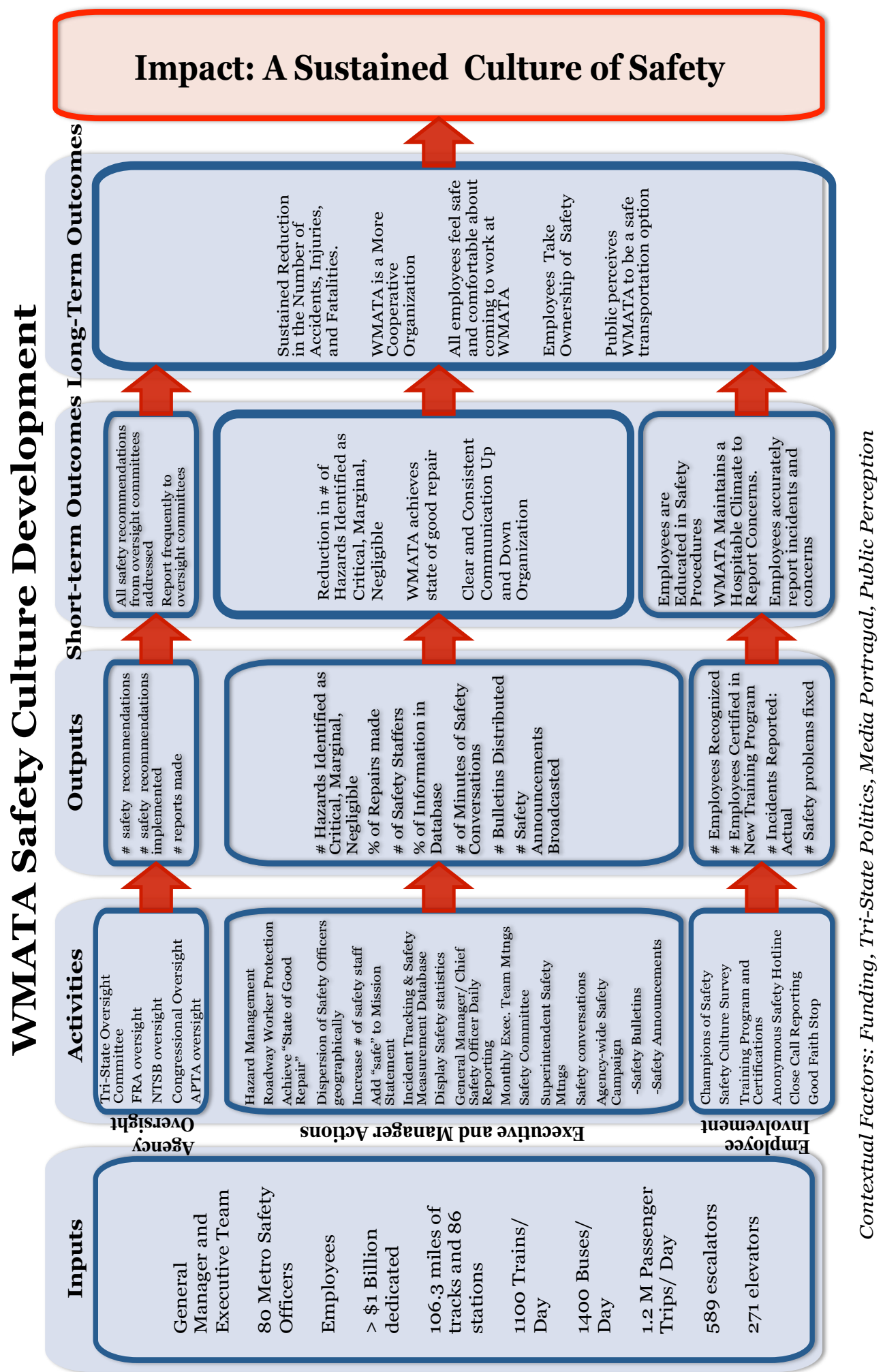


hiding what we're doing. We're sharing it with the media." However, the union's chief safety officer countered, "Employees feel sold out when incidents happen and they hit the media - instead of bringing employees in to find out what happened" (Interview with Chief Safety Officer 2011). This dissent indicates that while transparency within the organization seems positive, transparency outside of WMATA may yield unintended consequences.

\section{Foster a Spirit of Cooperation}

In an organization with as many departments and levels as WMATA, all parts of the organization must learn to work together. The safety trainer argued that the organization needs to foster a spirit of cooperation between supervisors and line employees to establish a shared goal of working safely. The union chief safety officer agreed that cooperation is essential, and he believes that WMATA still has room to improve, because "one department doesn't know what the other department is doing" (Interview with WAMTA Union Leader 2011). The level of cooperation directly affects the degree to which employees feel they can trust each other, their supervisors, and the system that is meant to keep them safe.

\section{Listen to Employees}

A few years ago, employees did not feel that the larger organization cared about or listened to them, so WMATA took steps to make employees feel valued and heard. A superintendent explained that he tries to get many people involved in safety committees so they feel invested in the change process. The union chief safety officer explained the importance of listening to employees: "Involve your workforce because they have answers to all of the issues that you're having in the workforce... and you can only find that out if your workers report to you" (Interview with WMATA Union Leader 2011). Thus, employee involvement both increases investment and provides valuable feedback to inform the change process.

One method of allowing employees a voice, the Good Faith Challenge, has received mixed reactions. The safety trainer reports that line employees love the Good Faith Challenge. He described one worker who had been asked to carry a door across four sets of tracks, including the electrified third rail. The worker was concerned that if he refused to do this, his supervisor would get someone else to do it. The trainer explained, "The employee didn't feel like they had any recourse. Some guys feel if they speak up and tell a supervisor, they'll be blacklisted, there will be retaliation. The Good Faith Challenge is designed to prevent retaliation" (Interview with Safety Trainer 2011). He continued that while some people may view this challenge as disruptive, WMATA favors a disruption to work over risking employees' death or dismemberment. While the trainer had not heard any negative response to this procedure from managers or line employees, he also did not know of any time this practice has been implemented. On the other hand, the union chief safety officer doubted that employees feel comfortable implementing this challenge, saying that people prefer to call their union representatives rather than stopping the work.

\section{Borrow Good Ideas}

WMATA benefitted from looking at other organizations and adopting their best practices. A superintendent said that WMATA developed its Roadway Worker Protection program after visiting other railroad companies and agencies to learn about their practices. The union chief safety officer also believes that it is important to look beyond one's own organization. Many other organizations were simultaneously refocusing efforts on safety culture. Exploring and adopting those ideas helps WMATA build upon others' promising practices.

\section{Conclusion}

This research highlights the prom- 
ising practices and strategies that Amtrak and WMATA have used during the development of sustained cultures of safety. In certain cases, the findings highlight points of disagreement between the interviewees over whether certain practices and strategies are proving successful. The goal of the research was not to prove the efficacy of any practices or strategies, but rather to represent a broad range of views and opinions concerning which practices and strategies lead to beneficial outcomes in each organization.

Amtrak and WMATA employed different approaches to transform their safety cultures. Amtrak's method can be broadly defined as behavior-based. Many of Amtrak's activities, as part of Safe-2-Safer, concentrate on changing behavior that only have an indirect relationship to safety. Amtrak is changing the fundamental, underlying behaviors of its managers and employees to improve its safety culture. WMATA's more limited approach concentrates on improving safety processes and practices. Essential to WMATA's approach is an emphasis on training employees on safe behavior. No one-size-fits-all approach exists for developing a safety culture. Every organization has unique objectives, stakeholder challenges, and resources constraints. However, some common themes emerged in the development of safety cultures within Amtrak and WMATA. Developing a sustained culture of safety requires significant organizational commitment at all levels because organizational cultures are deeply embedded and difficult to change. If significant stakeholders do not buy into the change process, it has little chance of success. To achieve stakeholder buy-in, organizations need a highly influential leader to champion the change process. WMATA and Amtrak agree that the commitment to transformative change must radiate from CEO level.

Amtrak and WMATA recognized the importance of becoming a more collaborative organization. One common ele- ment that illustrates this collaboration is the shift toward learning and away from finding blame and levying punishment. If managers are focused on finding blame for an accident, they may ignore the contributing factors, thus perpetuating the problem that created the accident. Also, concentrating on punishment tends to foster cynical, "us against them" attitudes in employees, which is antithetical to establishing a safety culture. Collaborative organizations develop systems to allow employees to communicate up the chain of command. Each organization highlighted the need for anonymity in allowing employee voices to be heard, especially in relation to safety incident reporting. Transparency and information sharing increased cooperation within each organization. Sharing safety weaknesses and safety performance data builds employee trust in management and the organization. Creating a collaborative culture fosters organizational citizenship behavior in each employee, wherein employees embrace an intrinsic commitment to improving the organization.

Although their processes differed, both Amtrak and WMATA were working toward NTSB's recommendations that an effective organization be informed, reporting, just, and learning. Both organizations became more informed through their employee trainings and observations. They created systems to gather more accurate reporting through a variety of identifiable and anonymous methods. They endeavored to become more just by removing negative repercussions for reporting safety incidence. Finally, they sought to improve organizational learning by closely tracking safety problems and finding ways to mitigate them.

These case studies identify promising practices and lessons learned from each organization, as well as the perceived strengths and weaknesses of the safety culture development processes. Future studies should involve a rigorous evaluation of which strategies have proven effective, 
including in-depth analysis of the incident and incident reporting rates for each organization. Surveying managers and employees would yield a more complete picture of how pervasively the culture shifted in each organization. Although this study cannot state conclusively that the organizations have succeeded, the research team believes that both Amtrak and WMATA are making significant progress toward developing sustained cultures of safety.

\section{References}

Amtrak. 2007. "Amtrak Safety Program.” Washington, DC: Amtrak.

Amtrak. 2009. “2008 Environmental Health \& Safety Report.” Washington, DC: Amtrak.

Amtrak. 2010a. “2009 Environmental Health \& Safety Report.” Washington, DC: Amtrak.

---. 2010b. "Fiscal Year 2011 Revised Budget and Comprehensive Business Plan." Washington, DC: Amtrak.

- - . 2010c. "FY 2010-2014 Five Year Financial Plan." Washington, DC: Amtrak.

Coplen, M., Ranney, J., Zuschlag, M. 2007. "Behavior-Based Safety at Amtrak-Chicago Associated with Reduced Injuries and Costs." US Federal Railroad Administration.

Department of Transportation. 2010. "Safety Council Safety Culture Proposal."

Halsey, A. III. 2011. "Possible loss of federal funding puts Metro overhaul at risk." The Washington Post, March 28. http://www.washingtonpost.com/local/possibleloss-of-federal-funding-puts-metro-overhaul-at-risk/2011/o3/28/AFxdz2qB_ story.html.

Hedgpeth, Dana. 2011. "Metro officials report gains in safety, training since 2009 Red Line crash.” The Washington Post, June 15. http://www.washington post.com/local/metro-officials-report-gains-in-safety-training-since2009-red-line-crash/2011/o6/15/AG32OYWH_story.html.

International Nuclear Safety Advisory Group. 1991. "Safety Culture." Safety Series No. 75-INSAG-4. Vienna: IAEA.

Interview with an Amtrak manager, April 8, 2011.

Interview with chief safety officer, April 7, 2011.

Interview with Joseph Boardman, March 23, 2011.

Interview with Safety Consultant, April 12, 2011.

Interview with Safety Trainer, May 26, 2011.

Interview with Union Leader, May 5, 2011.

Interview with WMATA superintendent, July 8, 2011.

Interview with WMATA Union Leader, July 29, 2011.

National Transportation Safety Board. 2010. "Collision of Two Washington Metropolitan Area Transit Authority Metrorail Trains Near Fort Totten Station Washington, DC, June 22, 2009.” July 27. http://www.ntsb.gov/doclib/re ports/2010/RAR1002.pdf.

Office of Performance. 2010. "Vital Signs Report: A Scorecard of Metro's

Key Performance Indicators (KPI)." Washington Metropolitan Transit Author ity.http://www.wmata.com/about_metro/docs/Vital_Signs_February_2011. pdf.

Ranney, J., Nelson, C., Coplen, M. 2005. "The Efficacy of Behavior-based Safety in the US Railroad Industry: Evidence from Amtrak-Chicago." 
Washington, DC: US Federal Railroad Administration.

Scott Tyson, A. 2010. "NTSB blames 'o9 Metro crash on track circuit failures, negligent safety attitude." The Washington Post, July 28. http://www. washingtonpost.com/wp-dyn/content/article/2010/07/27/ AR2010072706080.html?sid=ST2011030805637.

Shultz, D. 2011. "While DC Metro Police face cutbacks, federal anti-terror funds flow." Transportation Nation, June 23. http://transportationna tion.org/2011/o6/23/while-dc-metro-police-face-cutbacks-federal-antiterror-funds-flow/.

Sumwalt, R. 2009. "A Practical Look at Developing and Maintaining a Safety Culture." Washington, DC: National Transportation Safety Board, November 3. http://www.ntsb.gov/doclib/speeches/sumwalt/FSF_ IASS\%2oBeijing.pdf.

Tri-State Oversight Committee. "Tri-State Oversight Committee - State Safety Oversight.” http://www.tristateoversight.org/about.asp.

Washington Metropolitan Transportation Authority. 2008. "Comprehensive Annual Financial Report for the Fiscal Year Ended June 30, 2008.” http://www.wmata.com/about_metro/docs/cafr_FYo8.pdf. 
Mark Buckley graduated from the Master of Public Administration program at The George Washington University in 2011. He currently works as a business analyst with the consulting firm ICF International in the Homeland Security and Program Management division. Prior to completing his MPA, Mark worked at Columbia University in both admissions and career development. He earned his Bachelor of Arts degree in History from Boston College in 2003.

Keith Marfione is a second year Master of Public Administration student at The George Washington University, concentrating in Organizational Behavior and Leadership. He currently works as an analyst in the Office of Policy at the Department of Veterans Affairs. Prior to beginning graduate school, Keith served as a Field Artillery Officer in the Army and earned a Bachelor of Science in Political Science from the United States Military Academy at West Point.

Hannah Putman is in her second year of the Master of Public Policy program at The George Washington University, where she is concentrating in education policy and evaluation. She currently conducts education research at Westat and previously taught seventh and ninth grade English in New York City. She holds Bachelor's degrees in English and Government and Politics from the University of Maryland, as well as a Masters in Teaching from Pace University.

The authors thank editors Kristin Hubing and Tanner Daniel for their thorough feedback and support. The authors also thank Dr. Kathy Newcomer for teaching us the nuances of program evaluation, introducing us to the field of safety culture, and encouraging us to publish this paper. Further, the authors thank Rick Kowalewski and Michael Coplen from the Department of Transportation for their valuable insight into safety culture and their advice during this study. Finally, the authors thank our friends and family for cheering us on during the long months and numerous revisions devoted to this study. 